Article

\title{
The Effect of Electromagnetic Stirring on the Microstructure Evolution of $\mathrm{Cu}-15 \%$ Co Alloy
}

\author{
Lin Zhang * ${ }^{*}$, Jinfeng $\mathrm{Yu}$, Wenbin Wang, Zhaolong Xiang and Engang Wang *
}

Key Laboratory of Electromagnetic Processing of Materials (Ministry of Education), Northeastern University, Wenhua Road, Shenyang 110819, China; xiaoxiao900126@126.com (J.Y.); robinwwb@126.com (W.W.);

xz15612@163.com (Z.X.)

* Correspondence: zhanglin@epm.neu.edu.cn (L.Z.); egwang@mail.neu.edu.cn (E.W.);

Tel.: +86-24-8368-3985 (L.Z.); +86-24-8368-1739 (E.W.)

Received: 10 October 2018; Accepted: 22 October 2018; Published: 24 October 2018

check for updates

\begin{abstract}
Cu}-15 \% \mathrm{Co}$ alloys have been synthesized by an induction furnace adopting electromagnetic stirring (EMS). The liquid-liquid separation behavior and the peritectic reaction under a forced melt flow were analyzed. The specimens were subjected to a conventional induction melting as well as enhanced melt stirring by a two-side electromagnetic stirrer. The stirred ingots showed a significant improvement in dispersivity and homogeneity of the Co-rich phase. Comparing the specimens subjected to different current intensities, we observed strong changes in the phase fraction, the degree of segregation, and the grain size. EMS had an effect of reducing the amount and size of Co-rich droplets and enhancing the amounts of small equiaxed dendrites and dendrite fragments, which led to a more dispersive distribution of $\alpha$-Co phase and refined the grains of Cu-rich phase. We observed a considerable increase in the fraction of peritectic $\mathrm{Cu}$-rich phase with increasing current intensity of EMS, indicating that the peritectic reaction was promoted by EMS. EMS also reduced the macrosegregation of Co-rich phase in both the vertical and radial direction of the ingot when the current intensity was appropriate.
\end{abstract}

Keywords: Cu-Co; immiscible Alloy; electromagnetic stirring; liquid-liquid separation; peritectic reaction

\section{Introduction}

The solidification of immiscible alloys has always been a hard target for researchers because immiscible alloys are easy to form serious segregation, which is caused by a miscibility gap in the phase diagram. Because of the liquid-liquid separation, immiscible alloys are hard to be fabricated by conventional solidification. Since many immiscible alloys have good physical and chemical properties, these alloys have been studied for decades with different fabrication methods, such as the directional solidification [1,2], the rapid solidification [3,4], the solidification under microgravity in the space $[5,6]$ or on the ground $[7,8]$ etc. However, a homogenous structure was still hard to achieve in a bulk-size immiscible alloy by solidification, which limited its mass production and application.

This research prefers $\mathrm{Cu}-\mathrm{Co}$ alloy, which is used as a contact material $[9,10]$ and a potential giant magnetoresistance material [11,12]. Cu-Co alloys have been fabricated by researchers through different approaches. Rapidly quenched $\mathrm{Cu}$-Co ribbons showed substantially inhomogeneous microstructure with two types of Co-containing inclusions [13]. The melt-spun $\mathrm{Cu}_{100-x}-\mathrm{Co}_{x}$ alloys showed granular structures consisting of magnetic particles after annealing [14]. Cu-Co thin films prepared by DC magnetron sputtering consisted of ultrafine Co-rich precipitate particles in a Cu-rich matrix [15]. A pulsed electrochemical deposition method was used to fabricate $\mathrm{Cu}$-Co multilayered nanowires with $\mathrm{Co}$ and $\mathrm{Cu}$ layers [11]. Cu-Co melt processed by electromagnetic levitation had an undercooling larger 
than $200 \mathrm{~K}$, the microstructure showed Co-rich droplets due to phase separation [16]. Also, a high undercooling up to $220 \mathrm{~K}$ were acquired by melting the alloy together with purifier such as boron oxide [17]. The $\mathrm{Cu}-\mathrm{Co}$ alloys fabricated by the above approaches are limited by the small sample size. However, conventional solidification of bulk-sized $\mathrm{Cu}$-Co alloy leads to a heterogeneous structure. The Cu-Co alloy shows a metastable miscibility gap to generate liquid-liquid separation [18], which is the main cause of macrosegregation. The cobalt has a similar density as copper, which avoids the serious gravitational segregation of minority phase faced by most of the immiscible alloys, therefore $\mathrm{Cu}-\mathrm{Co}$ alloy has a higher probability to be fabricated into a dispersed structure without serious segregation. However, the segregation behaviors of the Co-rich phase still exist and has not been fully understood. The Co-rich phase transforms into droplets and dendrites respectively due to different reactions, followed by a peritectic reaction. The understanding of these behaviors is essential to further improve the homogeneity and refine the microstructure in $\mathrm{Cu}-\mathrm{Co}$ alloys.

A forced melt flow under stirring might be a way to improve the solidification structure and understand the role of melt flow in the solidification process. The electromagnetic stirring (EMS) is a non-contact mode of stirring, which has been widely applied to improve the solidification structure in various alloys. EMS has the effect to refine crystal grains and break up large dendrites in copper alloys $[19,20]$. Besides, EMS reduced the casting defects such as porosity, and improved the surface quality [21,22]. Strong stirring resulted in the removal of bulk liquid superheating, and lead to a relatively cold liquid on the solidification front [23]. EMS was used to eliminate the micro- and macrosegregation of solute elements in ingots [24,25]. Moreover, EMS applied to the solidification of metals led to the refinement and better distribution of precipitates [26,27]. EMS also can be used to refine the size of the minority phase in the immiscible alloy [28].

The microstructure of $\mathrm{Cu}$-Co alloy depends on the liquid-liquid segregation, the peritectic reaction and the transition of the solid phase. These solidification behaviors are processed in a liquid matrix; hence they are inevitably influenced by the melt flow. This thesis used a two-side electromagnetic stirrer to generate a forced melt flow in $\mathrm{Cu}-15 \% \mathrm{Co}$ alloy, and studied the effect of EMS on the fraction, distribution, and morphology of the Co-rich phase and the peritectic $\mathrm{Cu}$-rich phase.

\section{Materials and Methods}

All specimens were prepared from $99.97 \%$ pure copper and $99.95 \%$ pure cobalt. The alloys with a nominal composition of $\mathrm{Cu}-15 \% \mathrm{Co}$ (mass) were first prefabricated in a vacuum induction furnace, with an output of $50 \mathrm{~kW}$ and a frequency of $8 \mathrm{kHz}$. The specimens were melted at about $1650{ }^{\circ} \mathrm{C}$ for $2 \mathrm{~min}$. The melt was then cast into a copper mold with an inner diameter of $25 \mathrm{~mm}$ and an outer diameter of $200 \mathrm{~mm}$. The ingots were cut in the longitudinal direction twice perpendicularly into four parts. Then each quarter of the original ingots was used as a specimen to be melted in an induction furnace under the protection of argon and solidified in a graphite crucible. About $5 \mathrm{~g}$ boron oxide $\left(\mathrm{B}_{2} \mathrm{O}_{3}\right)$ was put to the surface of melt to further protect it from oxidization. Figure 1 shows the schematic diagram of the experimental set-up. A high-frequency induction furnace with an output of $40 \mathrm{~kW}$ and a frequency of $30 \mathrm{kHz}$ was used to remelt the alloy. An external magnetic field was applied in the form of two-side electromagnetic agitators. The induction coil and crucible were set between the two agitators, as shown in Figure 1. The samples were heated by the induction furnace to about $1600{ }^{\circ} \mathrm{C}$ and held for $2 \mathrm{~min}$. Then the furnace power was shut down and the melt was spontaneously cooled under protecting argon gas, with a cooling rate approximately $53{ }^{\circ} \mathrm{C} / \mathrm{s}$. The ingot of the $\mathrm{Cu}-\mathrm{Co}$ alloy had a diameter of $20 \mathrm{~mm}$ and a length of $30 \mathrm{~mm}$. The EMS was applied after the close of furnace power. The two agitators were set to generate horizontal magnetic forces with opposite directions in the melt, and the melt was observed to rotate horizontally under the EMS. In different experimental groups, the EMS was generated by a current set at a frequency of $16 \mathrm{~Hz}$ and different intensities of $100 \mathrm{~A}, 200 \mathrm{~A}$ and $300 \mathrm{~A}$ respectively, hence the max magnetic flux density changed with current intensity at the sample position, as shown in Figure $1 \mathrm{~d}$. 


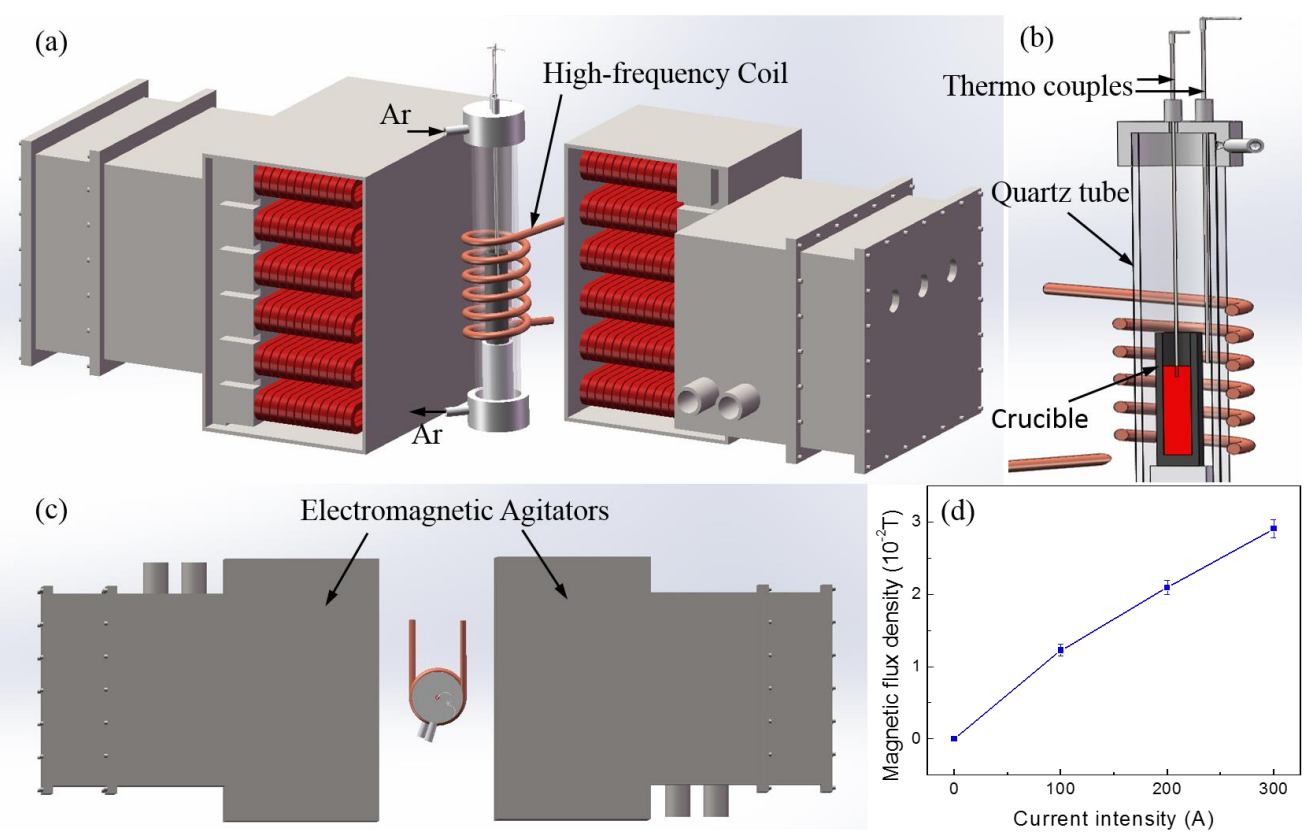

Figure 1. Schematic diagram of the experimental set-up for solidifying $\mathrm{Cu}-15 \% \mathrm{Co}$ alloy with electromagnetic stirring (EMS): (a) Stereoscopic view; (b) Cutaway view of the smelting part; (c) Plan view; (d) The max magnetic flux density changes with current intensity.

The chemistries in the final ingots were identified to be in the range of 15.1-15.3\% Co. Each ingot was subsequently sectioned longitudinally and etched to reveal the microstructure. The phases were identified by the X-ray diffraction analysis using a Philips X'Pert Pro MPD diffractometer (PANalytical Co., Almelo, The Netherlands). The microstructures were observed by the optical microscopy and the scanning electron microscopy (SEM) respectively. The optical microstructure was observed under a LeicaDMI 5000M microscope (Leica Microsystems, Wetzlar, Germany). The SEM images and the energy-dispersive X-ray spectroscopy (EDS) were carried out using a Superscan SSX-550 EDX scanning electron microscope (Shimadzu Corp., Kyoto, Japan). The electron backscattered diffraction (EBSD) and corresponding microstructures were analyzed using an Ultra Plus field emission scanning electron microscope (Carl Zeiss AG, Oberkochen, Germany). Image-Pro Plus software (Version 6.0, Media Cybernetics, Inc., Rockville, MD, USA) was used to analyze the size and the area fraction of phases.

\section{Results and Discussion}

$\mathrm{Cu}-\mathrm{Co}$ alloy has a metastable miscibility gap in the phase diagram which can result in the liquid-liquid separation and generate Co-rich droplets [18]. Outside the miscibility gap, Co-rich phase is formed as dendrite. Both Co-rich droplets and dendrites were observed in microstructure presented by Figure 2, in which the dark and bright regions were the Co-rich phase and Cu-rich phase, respectively. The spherical-shaped dark phase was transformed from the Co-rich droplet in the liquid-liquid separation, and the other dark phase was Co-rich dendrite. The droplets occurred in all the four experimental conditions (with different stirring currents: 0 A, 100 A, $200 \mathrm{~A}$, and $300 \mathrm{~A}$ respectively), whereas the size and amount of these droplets were different. As the increase of current intensity of EMS, the volume fraction of Co-rich dendrites tended to increase, and the amount and size of Co-rich droplets both decreased. 

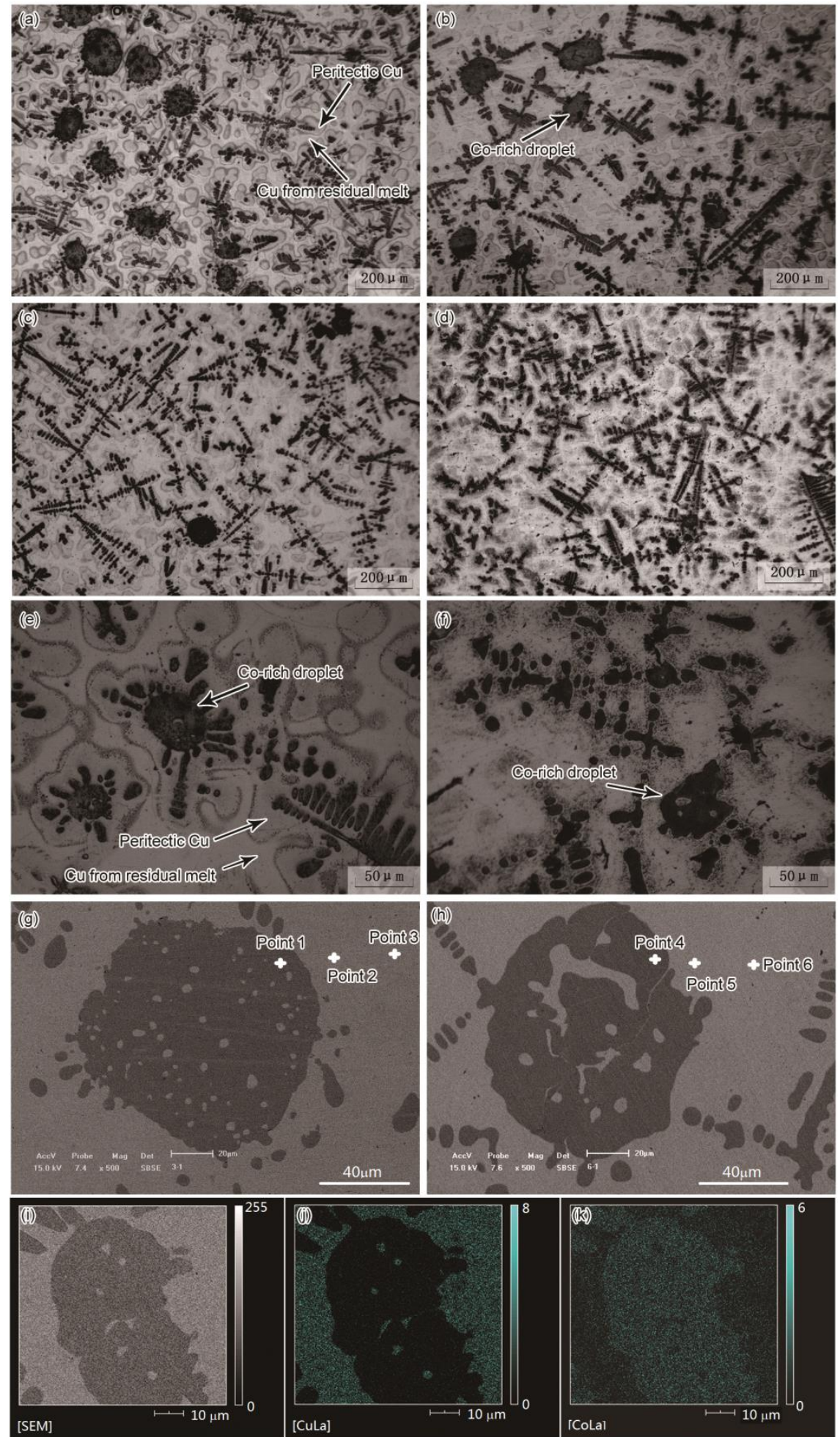

Figure 2. Microstructure of the Cu-Co ingot solidified without EMS (a), with EMS by setting current intensity at $100 \mathrm{~A} \mathrm{(b),} 200 \mathrm{~A} \mathrm{(c)} \mathrm{and} 300 \mathrm{~A}$ (d); A higher magnification of microstructure without EMS (e), with EMS of $300 \mathrm{~A}(\mathbf{f})$. The internal structure of Co-rich droplets without EMS (g) and with EMS of 300 A current (h) respectively; The scanning electron microscopy (SEM) image of a droplet in the ingot without EMS (i), and the results of energy-dispersive X-ray spectroscopy (EDS) mapping of element $\mathrm{Cu}(\mathbf{j})$ and $\mathrm{Co}(\mathbf{k})$ respectively. 
The EMS also had a large impact on the morphology of the liquid spheres, the droplets were broken apart into smaller ones by the EMS. Figure 2g,h present the backscattered electron (BSE) images of two Co-rich droplets with similar size, one is without EMS, the other is with an EMS of $300 \mathrm{~A}$ current. Both the two droplets underwent a secondary phase separation, leading to the occurrence of $\mathrm{Cu}$-rich particles inside the Co-rich droplets. Without EMS, the tiny $\mathrm{Cu}$-rich particles were distributed dispersively in the Co-rich droplet. Whereas, the $\mathrm{Cu}$-rich particles turned to be large and irregularly shaped in the sample with EMS of 300 A current. Without stirring, the droplet appeared to be a stable sphere (Figure 2g), indicating a steady state before it transformed into solid. With a strong stirring, the surface of the droplet was flushed by the melt flow and appeared to be unsteady, the droplet tended to be broken by the strong melt flow (Figure 2h). In this way, the EMS broke apart large droplets and reduced the droplets size. Small droplets were merged by the dendrite nucleating and growing on them, thus EMS tended to reduce the fraction of Co-rich droplets.

We measured the cobalt concentration around the droplets using EDS, as shown in Figure $2 \mathrm{~g}, \mathrm{~h}$. The concentrations of points 1-6 were $76.58 \%, 13.99 \%, 6.56 \%, 81.19 \%, 10.35 \%$, and $4.63 \%$ respectively, indicating that EMS enhanced the concentration discrepancy between Co-rich and Cu-rich phase, which might be caused by an enhanced mass transport in a forced convection. Figure $2 \mathrm{i}-\mathrm{k}$ show the results of EDS mapping in the zone around a Co-rich droplet. The $\mathrm{Cu}$-rich and Co-rich phase were distinctly identified. There were scanning points of Co element distributed in the Cu-rich matrix (Figure 2k), which is denser near the Co-rich phase, and sparser in the region far from the droplet, such as the region closed to the upper right corner of the image.

A peritectic reaction is supposed to be generated between the Co-rich solid and $\mathrm{Cu}$-rich liquid during the solidification process. The specimens were etched to show the region of peritectic $\mathrm{Cu}$ phase. There were two kinds of $\mathrm{Cu}$-rich phase distinctly show in Figure 2a-f, one was surrounding the Co-rich phase, the other was far from the Co-rich phase. We tested the composition of the two kinds of $\mathrm{Cu}$-rich phase using EDS. The $\mathrm{Cu}$-rich phase surrounding the Co-rich dendrites was identified to have a higher cobalt concentration in the range of $10.35-14.16 \% \mathrm{Co}$, which was the peritectic $\mathrm{Cu}$-rich phase generated by the peritectic reaction. Another kind of $\mathrm{Cu}$-rich phase was observed in the space between peritectic regions, which was measured to have a lower cobalt concentration in the range of $3.99-6.56 \%$ Co. This Cu-rich phase was transformed from residual melt after an incomplete peritectic reaction, indicating that only a part of $\mathrm{Cu}$-rich liquid took part in the reaction. Since the peritectic reaction was generated between the $\mathrm{Cu}$-rich liquid and the $\alpha$-Co solid, such a reaction depended on the solute transport between the solid and the liquid phase, which could be influenced by the strong melt flow generated by EMS.

We have analyzed the XRD patterns of the $\mathrm{Cu}$-Co alloys solidified in this experiment and found that EMS had no obvious effect on the XRD pattern. Figure 3 presents XRD patterns of the specimen without and with EMS. The XRD results revealed that the Co-rich phase in the ingot is $\alpha$-Co, which has not transformed into $\varepsilon$-Co from face-centered cubic (f.c.c.) to hexagonal close-packed structure (h.c.p.) through the allotropic transformation. Both the droplets and dendrite consisted of $\alpha$-Co phase. We measured the composition of different Co-rich phases using EDS, the result revealed that Co-rich dendrites contained $82.79-93.44 \%$ Co, and Co-rich droplets contained $76.58-84.19 \%$ Co. The average cobalt concentration of spherical Co-rich particles was lower than that of the Co-rich dendrites.

The morphology of $\alpha$-Co phase in the solidification structure depended on several different reactions. Figure 4 shows a phase diagram of $\mathrm{Cu}$-Co alloy together with its schematic diagram of the solidification process, in which an arc-shaped metastable miscibility gap exists below the liquidus line. When the liquid $\mathrm{Cu}-\mathrm{Co}$ is cooled into this region, it separated into Co-rich liquid $\left(\mathrm{L}_{1}\right)$ and $\mathrm{Cu}$-rich liquid $\left(\mathrm{L}_{2}\right)$. The solidification routes of $\mathrm{Cu}-\mathrm{Co}$ alloy have been studied by many researchers [29-32]. A metastable miscibility gap exists below a certain temperature resulted in the separation of the melt into two liquids [31]. Isolated droplets of minority liquid phase coarsen and grow in a spherical shape to minimize surface energy [30]. Owing to recalescence, the droplet-shaped particles have a chance to coexist with the $\alpha$-Co dendrites in the microstructure [32]. 

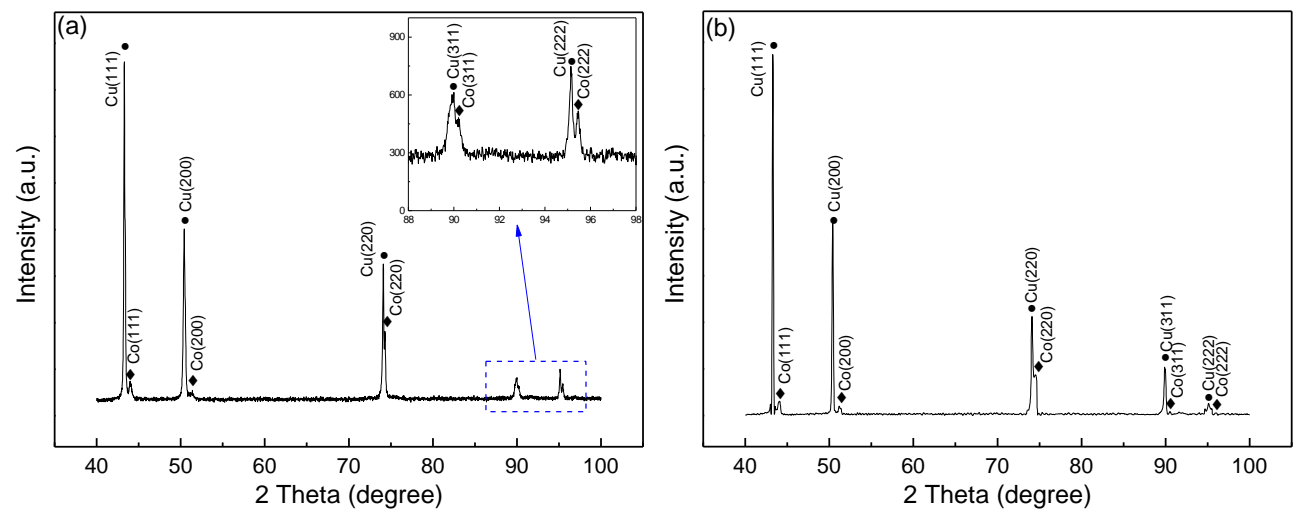

Figure 3. The X-ray diffraction (XRD) pattern of a Cu-15\%Co alloy: (a) without EMS; (b) with EMS of $200 \mathrm{~A} / 16 \mathrm{~Hz}$.

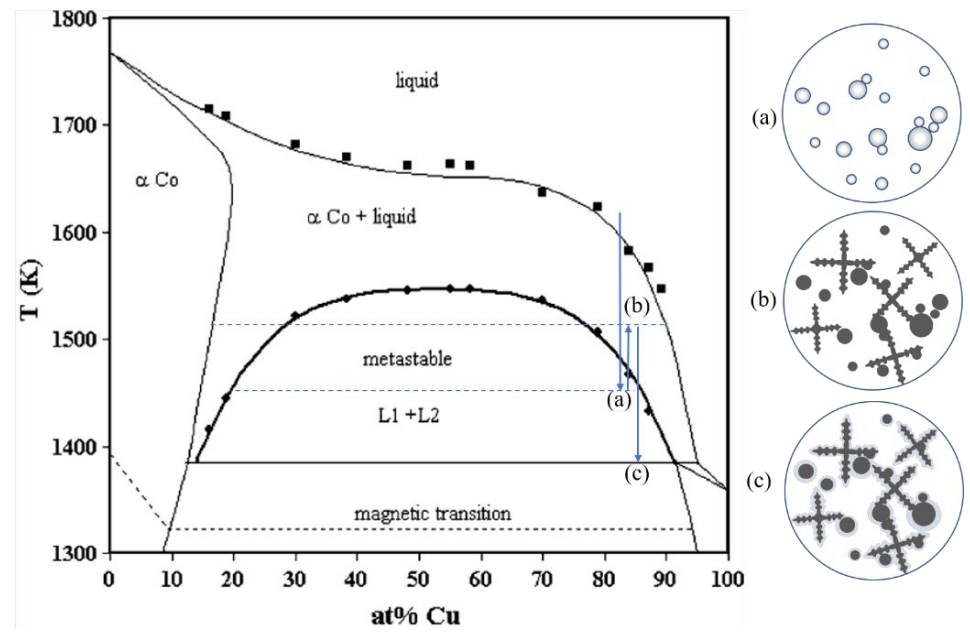

Figure 4. This is a phase diagram schematic of $\mathrm{Cu}-\mathrm{Co}$ (reproduced from [29], with permission from Springer Nature, 2018). and the schematic diagram of the solidification process: (a) Nucleation, collision, and coagulation of Co-rich droplets; (b) Nucleation and growth of $\alpha$-Co dendrites, and Co-rich droplets also turn to be $\alpha-\mathrm{Co}$; (c) Peritectic reaction between $\alpha$-Co and $\mathrm{Cu}$-rich matrix.

The specimens in all the four experimental conditions contained spherical Co-rich phase in the microstructure, indicating that the melt has entered the miscibility gap. The cooling rate was measured to be $53 \mathrm{~K} / \mathrm{s}$, and the undercooling was estimated to be about $120 \mathrm{~K}$ (The minimum undercooling for liquid phase separation of $\mathrm{Cu}-15 \% \mathrm{Co}$ alloy is $113 \mathrm{~K}$ according to Figure 4$)$. This undercooling might be caused by the boron oxide layer on the melt surface, which has an effect to absorb the tiny impurity particles in the melt. Thus, it might suppress the nucleation and enhance the undercooling. There was no significant discrepancy of undercooling between different EMS conditions. The solidification process included three stages mainly: (a) Liquid-liquid separation prior to solid nucleation. When the melt was cooled below the metastable miscibility gap, phase separation initially appeared as many small Co-rich droplets dispersed within the $\mathrm{Cu}$-rich liquid. The droplets of the minority phase migrated in the melt under the effect of gravity, the interface tension, and the melt flow [33]. The droplets impinged upon one another, and further resulted in the increase of droplet size. (b) Recalescence and formation of Co-rich dendrites. The heat released by the liquid-liquid separation raised the liquid temperature, both $\mathrm{L}_{1}$ and $\mathrm{L}_{2}$ were out of the region of the miscibility gap and the system was in a miscible state again. $\mathrm{L}_{1}$ Co-rich droplets tended to transform into $\alpha$-Co solid phase and released more heat, which further increased the liquid temperature. This process due to heat release is recalescence. If the temperature of the melt was above the miscibility gap again, Co-rich dendrites were forming in the matrix, which grew along with the spherical $\alpha$-Co phase. The solidus line has a higher cobalt 
fraction than the immiscibility boundaries of $\mathrm{L}_{1}$ liquid, therefore $\alpha$-Co dendrites tend to have a higher cobalt concentration than the Co-rich droplets. (c) Peritectic reaction. When the liquid temperature reached the peritectic temperature, a peritectic reaction took place and a peritectic $\mathrm{Cu}$-rich solid phase occurred between the $\alpha$-Co phase and the liquid $\mathrm{Cu}$-rich matrix. Since the peritectic $\mathrm{Cu}$-rich phase was a solid phase and the diffusion was relatively slow, the solid $\mathrm{Cu}$-rich phase created a diffusion barrier and the peritectic reaction proceeded at an ever-decreasing rate. In this experiment, there was some residual $\mathrm{Cu}$-rich liquid that had not participated in the peritectic reaction, which solidified into the residual $\mathrm{Cu}$-rich phase with a different cobalt concentration compared with the peritectic $\mathrm{Cu}$-rich phase (Figure 2a-f).

Figure 5 a presents the relation between the current intensity and the fraction of the peritectic $\mathrm{Cu}$-rich phase to the whole $\mathrm{Cu}$-rich matrix. The fraction increased with increasing current, indicating that the peritectic reaction was accelerated by the EMS, which was caused by the enhancement of mass transport in a forced melt flow. Figure $5 b$ shows the fraction of spherical Co-rich particles changed with the current intensity of EMS. The volume fraction decreased with increasing current intensity, indicating that a strong melt flow tended to reduce the fraction of Co-rich droplets during solidification. As discussed above, the large droplets were broken up by the forced flow into smaller droplets and later merged by the growing dendrites. Figure $5 \mathrm{c}$ shows the statistic of the dendrite length under different experimental conditions. EMS broke up long dendrites and reduced the dendrite size. As the stirring current increased, the dendrite length tended to have a higher probability density in the range of 20-180 $\mu \mathrm{m}$, which corresponded to small size dendrites or fragments, indicating that some dendrites were broken into fragments by the EMS. However, the dendrite lengths in all the four experimental conditions have similar distribution range, which meant there were still many long dendrites keeping unbroken even in a forced flow. The peak position in Figure 5c was not regularly moved left with increasing current intensity. The region of 90-150 $\mu \mathrm{m}$ was around the peak position and included most of the short dendrites, which had a smaller possibility to be broken by the EMS with current smaller than 200 A. Instead, the dendrite growth tended to be accelerated by the high solute transport under the forced flow. This might move the peak position slightly to the right side. However, some dendrites in this region tended to be broken by the EMS with a current of $300 \mathrm{~A}$, which moved the peak to the left side.

Figure 6 shows the images of electron backscatter diffraction (EBSD) and the corresponding FESEM images of the specimens with and without EMS. Both the FESEM images contained multiple dendrites, some of which appeared to be equiaxed dendrites or fragments. Several long dendrites in the 0 A specimen tended to link closely with each other, while the dendrites in the 200 A specimen were distributed dispersively. Since the $\mathrm{Cu}$-rich phase was initially generated around the $\alpha$-Co phase thorough peritectic reaction, the amount and size of $\alpha$-Co dendrites and droplets tended to affect the formation of $\mathrm{Cu}$-rich grains. As discussed above, the peritectic $\mathrm{Cu}$-rich phase surrounded $\alpha$-Co dendrites and droplets by nucleating and growing on them. Later, the residual melt also transformed into the solid state and surrounded the peritectic $\mathrm{Cu}$-rich region. As revealed by the EBSD results (Figure 6c,d), the Cu-rich matrix was composed of grains with different orientations. The peritectic and residual $\mathrm{Cu}$-rich phases were of the same crystal orientation and formed one grain when they surrounded one dendrite. Because the small $\alpha$-Co dendrite fragments distributed dispersively in the 200 A specimen, there were some small grains forming around these $\alpha$-Co fragments. 

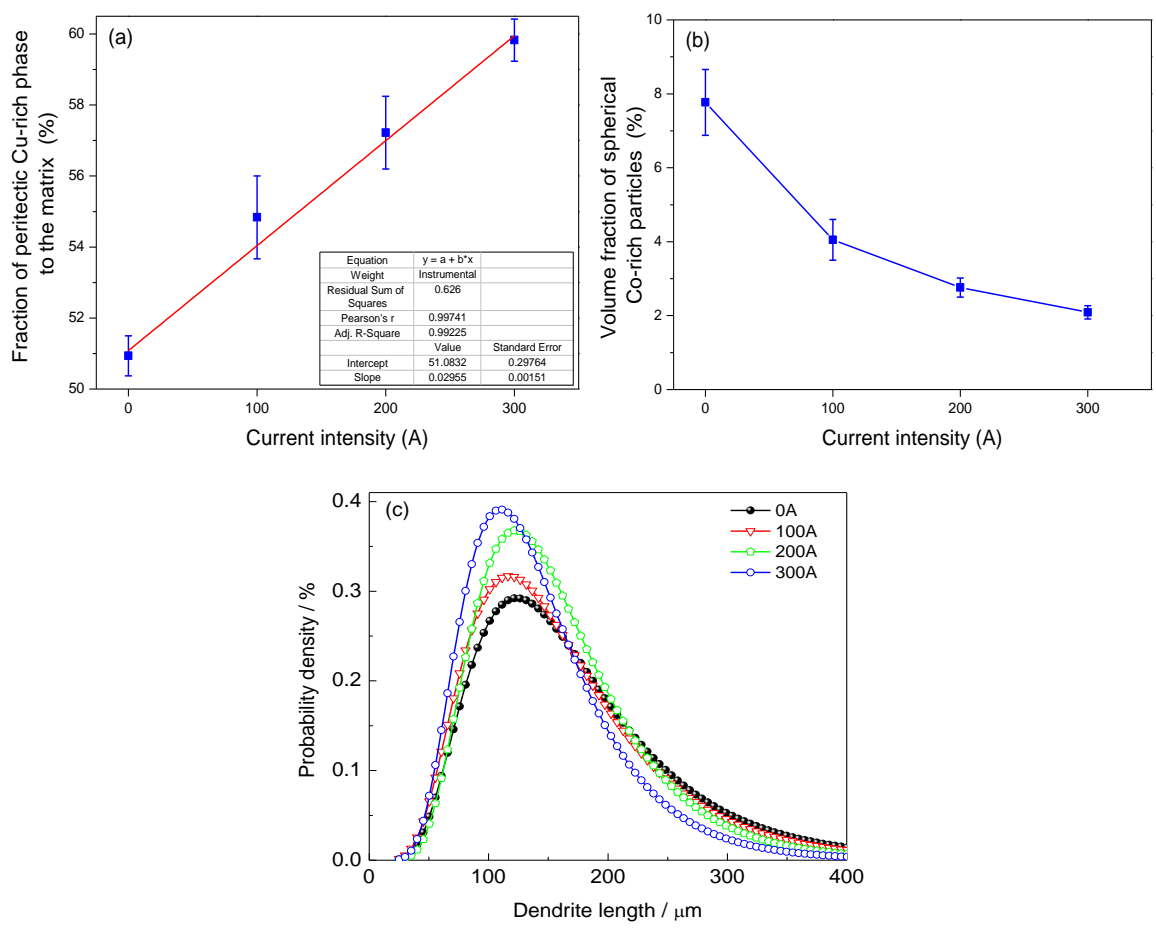

Figure 5. This is the statistic results analyzed from the microstructures: (a) The fraction of peritectic Cu-rich phase changed with the current intensity of EMS; (b) The fraction of spherical Co-rich particles changed with the current intensity of EMS; (c) Probability density of $\alpha$-Co dendritic length under four different stirring current intensity. The red line is the linear fit line.
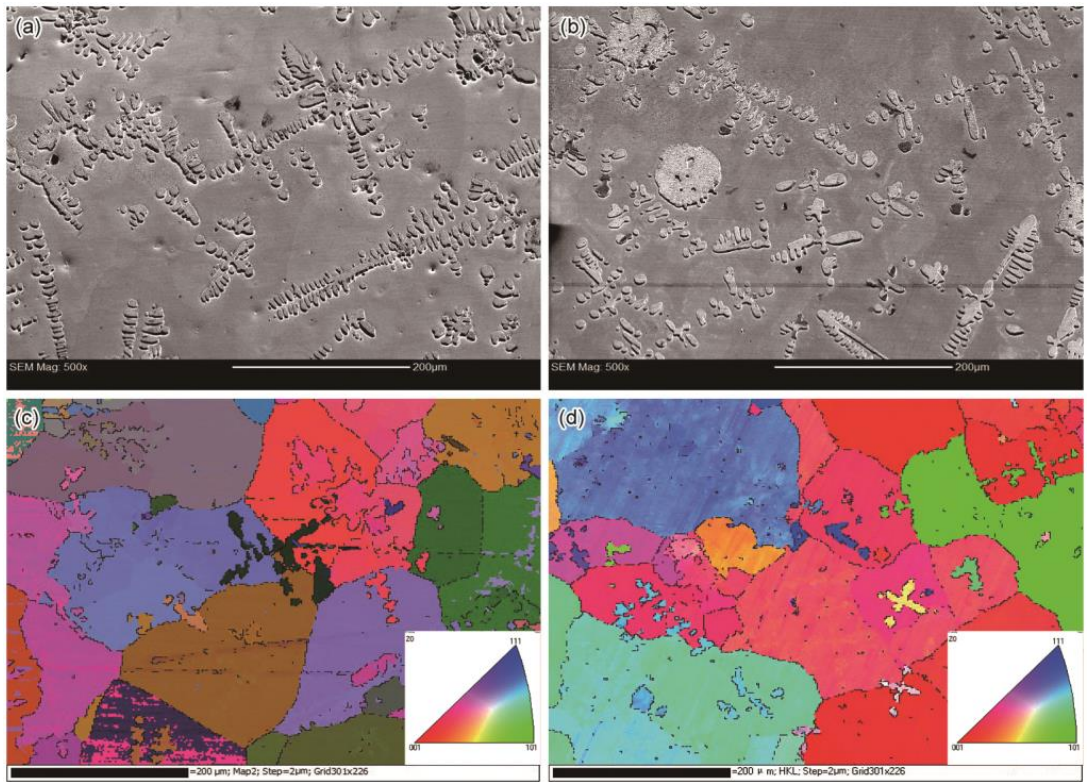

Figure 6. Electron Backscattered Diffraction (EBSD) orientation image of the $\mathrm{Cu}-15 \% \mathrm{Co}$ alloys and the corresponding field emission scanning electron microscopy (FESEM) micrographs: (a) FESEM image of specimen without EMS; (b) FESEM image of specimen stirred with current $16 \mathrm{~Hz} / 200 \mathrm{~A}$; $(\mathbf{c}, \mathbf{d})$ corresponding crystallographic maps to $(\mathbf{a}, \mathbf{b})$, with colors representing different crystal planes.

Although the density difference between cobalt and copper is small, there is still a possibility of macrosegregation during solidification of $\mathrm{Cu}-\mathrm{Co}$ alloy. We analyzed the macrosegregation by measuring the volume fraction of Co-rich phase (area fraction in the microstructure) in different positions, as shown in Figure 7. Without EMS, the ingot had a higher cobalt fraction in the top 
and bottom, and a lower fraction in the middle part. On the contrary, the middle part tended to have a higher cobalt fraction when the EMS was applied. By comparing the fractions in different specimens at the $15 \mathrm{~mm}$ height from the ingot base, we found that the cobalt area fraction increased with increasing stirring current in both the central and edge part. Figure 7a compares the phase fraction in the central part of different specimens. The discrepancy in the area fraction with different height tended to be small when the stirring current was set as $200 \mathrm{~A}$. The discrepancy in the edge part was also small when the stirring current was $100 \mathrm{~A}$ or $200 \mathrm{~A}$, as shown in Figure $7 \mathrm{~b}$. By comparing the fraction discrepancy in the radial direction, we also found the value having the smallest discrepancy between the center and edge part when the stirring current was $200 \mathrm{~A}$. The EMS tended to reduce the macrosegregation in both the vertical and radial direction of the ingot when the stirring current was set as $100 \mathrm{~A}$ and $200 \mathrm{~A}$. However, when the current intensity was enhanced to $300 \mathrm{~A}$, the enlarged discrepancy at different positions indicated a worse macrosegregation.
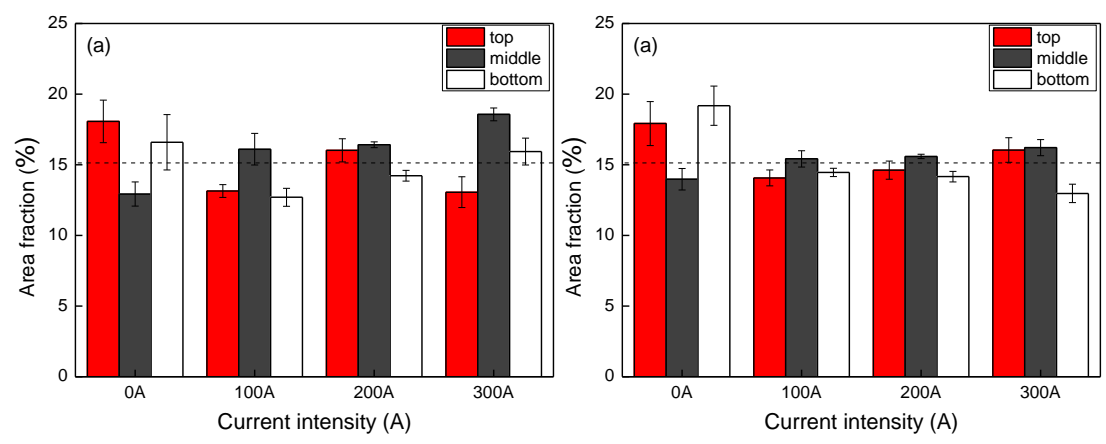

Figure 7. Area fraction of the Co-rich phase in different positions of samples with different stirring current: (a) Central part of ingot (on the central-axis); (b) Edge part of ingot ( $3 \mathrm{~mm}$ from the edge). The color bars represent different height (top: $25 \mathrm{~mm}$, middle: $15 \mathrm{~mm}$, bottom: $5 \mathrm{~mm}$ ) from the ingot base.

As revealed by Figure 2, the $\mathrm{Cu}$-rich phase closed to the $\alpha$-Co phase was generated by the peritectic reaction, which should have a higher cobalt concentration than the $\mathrm{Cu}$-rich phase transformed from the residual melt. Figure 8 shows the results of EDS line mapping of element cobalt along a dendrite arm and the surrounding $\mathrm{Cu}$-rich phase. There was an instant drop of cobalt concentration when the line mapping reached the $\mathrm{Cu}$-rich part, which was 115 counts for the specimen without EMS and 125 counts for the specimen with 200 A EMS, indicating that EMS enlarged the concentration discrepancy between $\mathrm{Co}$-rich and $\mathrm{Cu}$-rich phase. In the $\mathrm{Cu}$-rich phase, the cobalt concentration continued to drop in the direction far away from the Co-rich phase. There was a drop of 5 counts to the average level within a short distance in the specimen without EMS. However, the drop was 14 counts, but the concentration decreased monotonically within a larger distance in the 200 A specimen, indicating an enlargement of the region of peritectic $\mathrm{Cu}$-rich phase. The EMS enhanced mass transport through the liquids, which helped to adjust the compositions of the two liquids. Therefore, the two liquids followed the immiscibility boundaries and had a larger composition discrepancy compared with the case without EMS. The high mass transport also accelerated the peritectic reaction, resulting in the enlargement of the peritectic $\mathrm{Cu}$-rich region. 

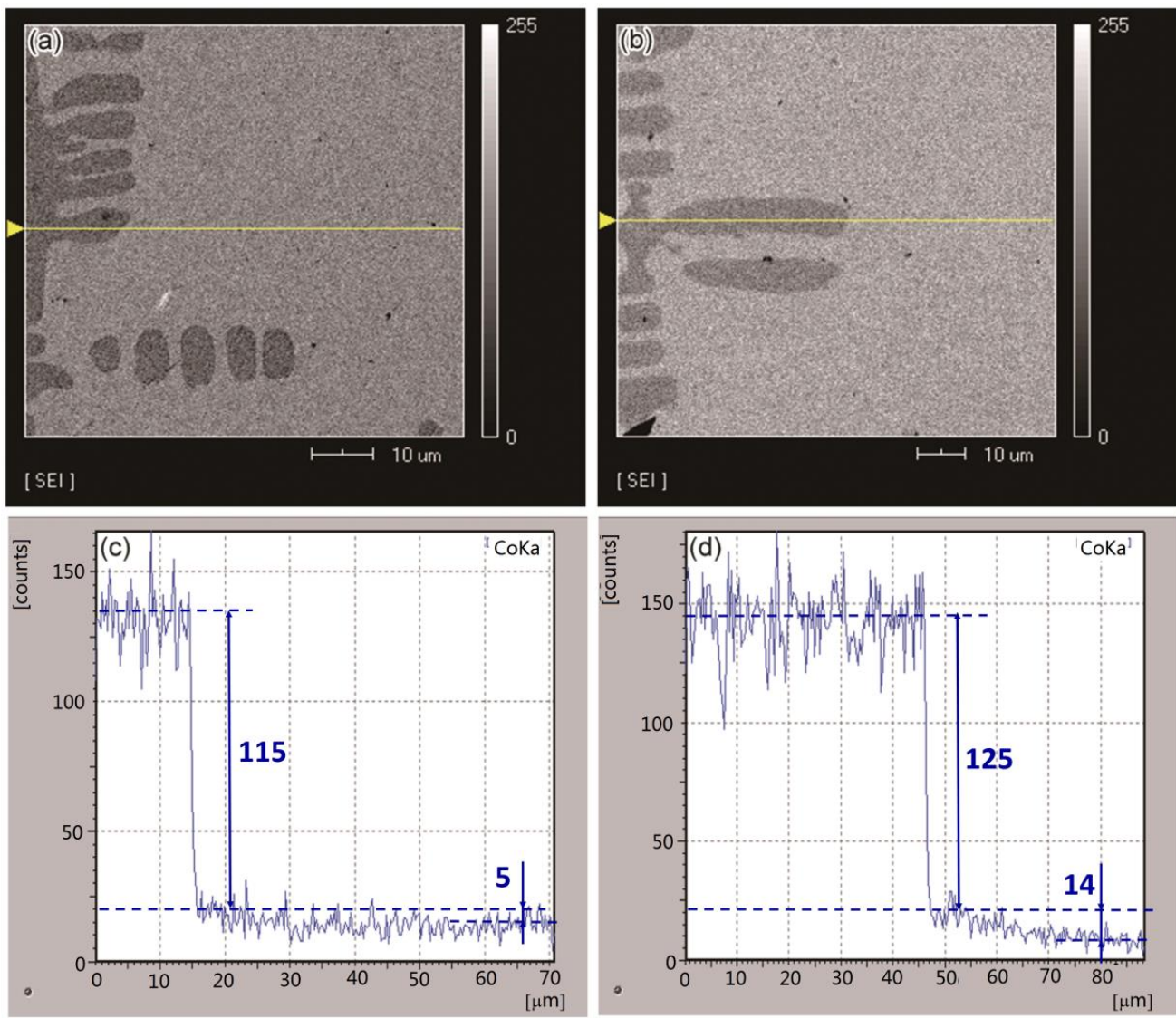

Figure 8. This is a schematic diagram of the EDS line mapping along the Co dendrite arm and extend into the Cu matrix: (a) without stirring; (b) stirring with current of $200 \mathrm{~A}$; (c,d) is the line mapping results of $(\mathbf{a}, \mathbf{b})$ respectively.

\section{Conclusions}

We have studied the effect of EMS on the liquid-liquid separation and the peritectic reaction of $\mathrm{Cu}$-Co immiscible alloys, the main conclusions can be summarized as follows:

The EMS reduced the amount and size of liquid Co-rich droplets during solidification, and the fraction of $\alpha$-Co dendrite increased with increasing stirring current intensity.

The Cu-rich matrix was composed of two kinds of $\mathrm{Cu}$-rich phase, one was generated by the peritectic reaction, and the other was from residual melt. EMS promoted the peritectic reaction and enhanced the fraction of the peritectic $\mathrm{Cu}$-rich phase. By surrounding one $\alpha$-Co droplet or dendrite, the two kinds of $\mathrm{Cu}$-rich phase were of the same crystal orientation and formed one grain.

The $\alpha$-Co phase was distributed more dispersively with EMS, and some dendrites were broken into fragments, which reduced the $\alpha$-Co dendrite size and led to the formation of some small Cu-rich grains.

The EMS tended to reduce the macrosegregation in both the vertical and radial direction of the ingot when the stirring current was set as $100 \mathrm{~A}$ and $200 \mathrm{~A}$. Whereas, an excessively high current such as 300 A caused a worse macrosegregation.

Author Contributions: Methodology, L.Z. and E.W.; Investigation, L.Z. and J.Y.; Formal Analysis, J.Y.; Data Curation, W.W. and Z.X.; Writing-Original Draft Preparation, L.Z.

Funding: This research was funded by the National Key R\&D Program of China-Intergovernmental Cooperation for Scientific Innovation, grant number [2017YFE0107900], the National Natural Science Foundation of China, grant number [51674083], and the Programme of Introducing Talents of Discipline to Universities (the 111 Project of China), grant number [B07015]. 
Conflicts of Interest: The authors declare no conflict of interest. The funders had no role in the design of the study; in the collection, analyses, or interpretation of data; in the writing of the manuscript, and in the decision to publish the results.

\section{References}

1. Silva, A.P.; Spinelli, J.E.; Garcia, A. Microstructural evolution during upward and downward transient directional solidification of hypomonotectic and monotectic Al-Bi. J. Alloy Compd. 2009, 480, 485-493. [CrossRef]

2. Yang, Z.Z.; Sun, Q.; Zhao, J.Z. Directional solidification of monotectic composition Al-Bi alloy. Acta Metal. Sin. 2014, 50, 25-31.

3. Luo, S.B.; Wang, W.L.; Chang, J.; Xia, Z.C.; Wei, B. A comparative study of dendritic growth within undercooled liquid pure $\mathrm{Fe}$ and $\mathrm{Fe}_{50} \mathrm{Cu}_{50}$ alloy. Acta Mater. 2014, 69, 355-364. [CrossRef]

4. Zhang, X.; Ruan, Y.; Wang, W.; Wei, B. Rapid solidification and dendrite growth of ternary Fe-Sn-Ge and Cu-Pb-Ge monotectic alloys. Sci. China Ser. G 2007, 50, 491-499. [CrossRef]

5. Carlberg, T.; Fredriksson, H. The influence of microgravity on the solidification of $\mathrm{Zn}-\mathrm{Bi}$ immiscible alloys. Metall. Trans. A 1980,11A, 1665-1676. [CrossRef]

6. Huang, Q.; Luo, X.H.; Li, Y.Y. An alloy solidification experiment conducted on Shenzhou spacecraft. Adv. Space Res. 2005, 36, 86-91. [CrossRef]

7. Wang, N.; Zhang, L.; Peng, Y.L.; Yao, W.J. Composition-dependence of core-shell microstructure formation in monotectic alloys under reduced gravity conditions. J. Alloy Compd. 2016, 663, 379-386. [CrossRef]

8. Jegede, O.E.; Cochrane, R.F.; Mullis, A.M. Metastable monotectic phase separation in Co-Cu alloys. J. Mater. Sci. 2018, 53, 11749-11764. [CrossRef]

9. Li, Y.H.; Guo, Z.C.; Huang, B.F.; Huang, H. Feasibility analysis of electrodeposited Cu-W-Co alloys. Adv. Mat. Res. 2014, 881-883, 702-707. [CrossRef]

10. Gabor, M. Trends in research of contact materials. Elektrotechnika 1982, 75, 135-137.

11. Le, T.C.; Yoon, H.; Chen, L.F.; McCann, R.C.; Varadan, V.K. Fabrication of giant magneto resistance sensing devices with vertically grown $\mathrm{Co} / \mathrm{Cu}$ nanowires on a substrate. J. Micro Nanolithogr. Mems. Moems. 2009, 8, 043055. [CrossRef]

12. Rajasekaran, N.; Mohan, S.; Chelvane, J.A.; Jagannathan, R. Giant magnetoresistance (GMR) and ferromagnetic properties of DC and pulse electrodeposited Cu-Co alloys. J. Magn. Magn. Mater. 2012, 324, 2983-2988. [CrossRef]

13. Vas'kovskii, V.O.; Kurlyandskaya, G.V.; Anton, R.L.; Sorokin, A.N.; Andreev, S.V.; Penya, A.; Podkorytov, M.A. Magnetic and magnetoresistive properties of rapidly quenched Co-Cu ribbons. Phys. Met. Metallogr. 2001, 92, 225-231.

14. Allia, P.; Knobel, M.; Tiberto, P.; Vinai, F. Magnetic properties and giant magnetoresistance of melt-spun granular $\mathrm{Cu}_{100-\mathrm{x}}-\mathrm{Co}_{\mathrm{x}}$ alloys. Phys. Rev. B. 1995, 52, 15398-15411. [CrossRef]

15. Berkowitz, A.E.; Mitchell, J.R.; Carey, M.J.; Young, A.P.; Zhang, S.; Spada, F.E.; Parker, F.T.; Hutten, A.; Thomas, G. Giant magnetoresistance in heterogeneous Cu-Co alloys. Phys. Rev. Lett. 1992, 68, 3745-3748. [CrossRef] [PubMed]

16. Zhang, Y.K.; Gao, J.; Wei, L.L.; Kolbe, M.; Volkmann, T.; Herlach, D. Novel insight into microstructural evolution of phase-separated Cu-Co alloys under influence of forced convection. J. Mater. Sci. 2011, 46, 6603-6608. [CrossRef]

17. Yang, W.; Chen, S.H.; Yu, H.; Li, S.; Liu, F.; Yang, G.C. Effects of liquid separation on the microstructure formation and hardness behavior of undercooled Cu-Co alloy. Appl. Phys. A 2012, 109, 665-671. [CrossRef]

18. Palumbo, M.; Curiotto, S.; Battezzati, L. Thermodynamic analysis of the stable and metastable Co-Cu and Co-Cu-Fe phase diagrams. Calphad 2006, 30, 171-178. [CrossRef]

19. Yan, Z.; Liu, H.; Li, T.; Zhang, X.; Cao, Z.; Zhang, X. Effects of alternating magnetic field and casting parameters on solidification structure and mechanical properties of copper hollow billets. Mater. Des. 2009, 30, 1245-1250. [CrossRef]

20. Li, H.; Jie, J.C.; Chen, H.; Zhang, P.C.; Wang, T.M.; Li, T.J. Effect of rotating magnetic field on the microstructure and properties of Cu-Ag-Zr alloy. Mater. Sci. Eng. A 2015, 624, 140-147. [CrossRef] 
21. Yamanaka, A.; Ota, K.; Terunuma, M.; Tsujita, S.; Abe, T. Reduction of center porosity of round billet by electromagnetic stirring in horizontal continuous casting. J. Iron Steel Inst. Jpn. 1998, 84, 609-616. [CrossRef]

22. Dong, Q.P.; Zhang, J.M.; Zhao, X.K. Prediction of columnar-To-equiaxed transition and porosity in continuous cast billet. Metall. Res. Technol. 2017, 114, 303. [CrossRef]

23. Griffiths, W.D.; Mccartney, D.G. The effect of electromagnetic stirring during solidification on the structure of Al-Si alloys. Mater. Sci. Eng. A 1996, 216, 47-60. [CrossRef]

24. Fu, Y.; Li, J.W.; Song, X.Y.; Zhang, Y.B.; Li, T.J. Restraining solute segregation of Al-1\%Si alloy in diverse physical field. Mater. Technol. 2012, 27, 173-175. [CrossRef]

25. Bo, L. The Segregation Behavior of Alloying Elements in the Al-5Fe-Based Alloys during the Semisolid Deformation. J. Miner. 2015, 67, 3030-3039. [CrossRef]

26. Jin, Y.L.; Du, S.L. Precipitation behaviour and control of TiN inclusions in rail steels. Ironmak. Steelmak 2018, 45, 224-229. [CrossRef]

27. Emmerich, H.; Siquieri, R.; Jurgk, M.; Rezende, J.; Hubert, J. A sharp interface model for the morphological evolution of precipitates in Al cast. Philos. Mag. Lett. 2007, 87, 863-869. [CrossRef]

28. Zhang, L.; Han, K.; Man, T.N.; Wang, E.G.; Zuo, X.W. Microstructural Evolution and Performance of In-situ Ag-Ni Composite after Solidification under Electromagnetic Stirring and Deformation. J. Iron Steel Res. Int. 2016, 23, 638-646. [CrossRef]

29. Egry, I.; Ratke, L.; Kolbe, M.; Chatain, D.; Curiotto, S.; Battezzati, L.; Johnson, E.; Pryds, N. Interfacial properties of immiscible Co-Cu alloys. J. Mater. Sci. 2010, 45, 1979-1985. [CrossRef]

30. Elder, S.P.; Munitz, A.; Abbaschian, G.J. Metastable liquid immiscibility in Fe-Cu and Co-Cu alloys. Mater. Sci. Forum 1989, 50, 137-150. [CrossRef]

31. Munitz, A.; Venkert, A.; Landau, P.; Kaufman, M.J.; Abbaschian, R. Microstructure and phase selection in supercooled copper alloys exhibiting metastable liquid miscibility gaps. J. Mater. Sci. 2012, 47, 7955-7970. [CrossRef]

32. Robinson, M.B.; Li, D.; Rathz, T.J.; Williams, G. Undercooling, liquid separation and solidification of Cu-Co alloys. J. Mater. Sci. 1999, 34, 3747-3753. [CrossRef]

33. Zhang, L.; Man, T.N.; Huang, M.H.; Gao, J.W.; Zuo, X.W.; Wang, E.G. Numerical simulation of droplets behavior of $\mathrm{Cu}-\mathrm{Pb}$ immiscible alloys solidifying under magnetic field. Materials 2017, 10, 1005. [CrossRef] [PubMed] 